Article

\title{
Embracing Variety in Decision-Making Regarding Adoption of Industry 4.0
}

\author{
Milou Habraken * and Tanya Bondarouk \\ Department of Human Resource Management, Faculty of Behavioural, Management and Social Sciences, \\ University of Twente, Drienerlolaan 5, 7522 NB Enschede, The Netherlands; t.bondarouk@utwente.nl \\ * Correspondence: m.m.p.habraken@utwente.nl
}

Received: 4 March 2020; Accepted: 6 May 2020; Published: 12 May 2020

\begin{abstract}
Industry 4.0 embodies the three technology-based developmental streams currently available and is widely recognised whether it is viewed as a great step forward or not. Consequently, the interest in the topic of "implementation" regarding Industry 4.0 has grown in recent years. However, data to date depict a somewhat single (technology-push, focused on organisational benefits) way of representing the drivers of Industry 4.0 adoption. In response, this paper intends to show to the scholarly and business communities that discussions in the literature on Industry 4.0 adoption drivers do not fully reflect the Industry 4.0 reality, which seems to us to be much more diverse. In other words, the goal is to provide an overview of the breadth and variation in drivers of Industry 4.0 adoption. This is achieved through assessing eight cases selected from the Dutch national and eastern regional platform for Industry 4.0. The cross-case analysis reveals the diversity in existing Industry 4.0 adoption drivers and highlights the apparent importance of the need-pull approach. It further highlights the relevant role that appears to be played by both internal supporting resources and external parties. Finally, it emphasises the diverse possibilities that the Industry 4.0 streams create.
\end{abstract}

Keywords: Industry 4.0; decision-making; technology adoption drivers; technology-push vs. need-pull; integrated approach

\section{Introduction}

In recent years, Industry 4.0 has become a frequently discussed topic among scholars and practitioners. The phenomenon has gained a great deal of interest over a relatively short period as visualised by various authors in a Google Trends curve. It also remains a somewhat vague concept surrounded by different meanings and understandings (Madsen 2019). Based on our research findings, Industry 4.0 appears to be a broad, overarching concept that often encompasses elements linked to technological components, a strategic vision, expected outcomes and/or essential preconditions. Given the operational impracticalities of such a construction, this paper considers Industry 4.0 as the three technology-based developments that are ongoing: (1) connected or "the establishment of connections between devices and/or systems within firms and with external parties worldwide"; (2) informed or "the ability to take more advantage of the value of information via the presence of greater amounts of data"; and (3) equipped or "the availability of contemporary physical and non-physical assets" such as 3D printing, drones or blockchains (Habraken and Bondarouk 2019, p. 13). By adopting this description, we take digitalisation into account as it is embedded in all three streams ${ }^{1}$, and we distance ourselves

"The emerging connections imply a digital format, the value in information becomes a critical factor because of the large quantities of information available as a result of data which has been transformed or is natively digital, and assets such as augmented reality require a digital component in order to function" (Habraken and Bondarouk 2019, p. 13). 
from the notion that Industry 4.0 is only intended for manufacturing processes. That is, the current technological developments are universally applicable and should not be constrained to a narrow type of process just because promotional platforms frame it as such.

By representing Industry 4.0 as the three technology-based developmental streams available to us, it is logical that "implementation" has become a popular aspect. That is, the aforementioned three streams exist and are widely known, and thus the debate now encompasses a means to apply them. It is therefore understandable that both management consultancies and scholars have focused on the creation of Industry 4.0 maturity models, evidenced in the recent sharp increase in the number of available models (Felch et al. 2019). Academic papers have been addressing the subject of implementation by assessing the challenges - including financial, technical, legal and cultural barriers-and drivers (e.g., Cordeiro et al. 2019; Hamada 2019; Moktadir et al. 2018; Müller et al. 2018a²; Orzes et al. 2018; Türkeş et al. 2019). With respect to the drivers of Industry 4.0 implementation, it is notable that findings reflect a technology-push (TP) approach. This approach emanates from the acknowledgement of new technologies as a means to improve firm performance and it requires, at minimum, an appreciation of what these new technologies potentially offer. It deals with potential benefits and is therefore rather opportunistic in nature (Munro and Noori 1988). Current findings state that Industry 4.0 enables decreases in costs, waste and repetitive work; increases speed, quality, flexibility and sales; and supports age-appropriate working environments (Hamada 2019³; Müller et al. 2018a; Türkeş et al. 2019). Thus, it reflects a technology-push approach.

Expressing the potential performance benefits of new technologies as a motive for making use of Industry 4.0 is, however, a rather one-sided way of representing the drivers of Industry 4.0 adoption. First, the TP approach can be interpreted more broadly than merely an enumeration of expected organisational benefits. Second, an alternative to the TP approach exists: the need-pull model (Chau and Tam 2000; Munro and Noori 1988). The need-pull (NP) model emphasises the needs of users, stressing that adoption is driven by recognised needs. This is not to deny that there are indications of alternatives to the technology-push approach in existing publications, such as: "keeps working on the old-fashioned way since this is their current competitive advantage" (Engelbertink and Woudstra 2017, p. 12), or "we distinguish between two categories of motives: internal ones derived from perceived market opportunities and external ones, derived from demands exercised by large customers" (Müller et al. 2018b, p. 9). However, such suggestions are scarce and fragmented.

The aim of this paper is therefore to provide an overview of the breadth and variation in drivers of Industry 4.0 adoption. This goal is achieved through assessing eight cases related to core Industry 4.0 organisations within the Netherlands. We acknowledge that this might appear a relatively small, and very localised, sample, but we are not pretending to show the full kaleidoscope of companies that have taken the Industry 4.0 route. Rather, this paper aims to show that the existing discussions on Industry 4.0 adoption drivers in the literature fail to fully reflect the Industry 4.0 reality, which to us seems to be much more diverse. By stressing the existing breadth, we aim to do justice to the complexity embedded in the process of decision-making and offer an understanding of why organisations differ in the manner in which Industry 4.0 is adopted. Further, we offer an alternative viewpoint (i.e., one unrelated to the barriers in the implementation process) on why the adoption of Industry 4.0 seems to be lagging behind expectations. Admittedly, there is little evidence available on Industry 4.0 adoption rates (Madsen 2019), but there are papers in which this conclusion seems to be drawn (Freese et al. 2018; Habraken et al. 2019; Huizinga et al. 2018; Müller et al. 2018a).

2 Although Müller et al. (2018a) do not offer any empirical data for the specific items pertaining to the challenges/drivers that they use, the paper is relevant since it does present the type of challenges/drivers that are assessed in their online questionnaire.

3 In our view, the aspects presented by Hamada (2019) under 'achievement by adapting to Industry 4.0' (Table 5, p. 10) are potential benefits since the paper presents no proof that the organisations have actually realised these achievements. 


\section{Technology Adoption Drivers}

\subsection{Technology-Push}

The technology-push approach is one way of looking at the decision to adopt Industry 4.0. As mentioned earlier, it stems from the recognition of new technologies as a means to improve the performance of an organisation and requires at least an appreciation of what these new technologies can potentially offer (Munro and Noori 1988). Despite the fact that new technologies often have the potential to significantly improve business operations, the danger with this approach is that firms can "become somewhat blinded by the immediate benefits of the technology at the expense of adequately addressing how those benefits can assist in meeting particular needs of the firm" (Munro and Noori 1988, p. 63) - a warning that appears valid in today's Industry 4.0 context given that Machado et al. (2019, p. 1117) concluded that "companies are jumping into technical matters, which could be necessary to show its possibilities and benefits, but it may be problematic if they forget to do the investigation about what they want to achieve, how the competitive priorities can benefit from digitalisation, and what changes need to be performed". It can thus be questioned whether this TP approach will result in the expected successes. Despite these questions, it is a concept that can be tied to Industry 4.0, as outlined in the introduction, and indeed to earlier technological developments. For instance, Munro and Noori (1988) found that $18 \%$ of their respondents employed a TP approach in justifying the automation of their manufacturing processes (e.g., lower costs, greater control over quality, more flexibility). In addition, in their multi-level study into the diffusion of robotic surgery in the Italian healthcare system between 1999 and 2010, Compagni et al. (2015) observed motivational drivers such as "expected technical benefits" from both a surgeons' perspective (distance surgery, reduced fatigue and ease of learning) as well as from a patient's viewpoint (reduced post-surgical pain, quicker recovery and reduced loss of blood). The view that new technologies can create organisational benefits may come from firms themselves but may also stem from influential third parties (such as the media). The latter option appears to be fitting to Industry 4.0, since it is a trending concept surrounded by considerable promotional communications from influential sources (the Dutch Industry 4.0 platform includes, for instance, the Ministry of Economic Affairs, a renowned research institute and a large employers' organisation), that are often formulated in a technology-push related manner.

Thus far, the focus of the technology-push approach has been on clear statements of expected performance, or organisational benefits, of a new technology. However, a more extensive interpretation of the TP approach can be given by emphasising "the minimum requirement" - that is, an appreciation of what new technologies can potentially offer. This is evident from the motivational driver "propensity to innovation" observed by Compagni et al. (2015), which was split into a surgeon's (or manager's) openness to new technologies/innovation, and their fascination with technology (containing emotional responses to, and imaginative stimulation of, robotic surgery). In other words, it reflects a favourable value or preference for technological development held by an individual who can influence the behaviour of people (Beyer 1981). So while this interpretation does not contain concrete benefits related to business success, it does encompass the notion of new technologies possessing beneficial capabilities (for why else would one be open, passionate and dreaming about them?) which can push action. We therefore consider this to be part of the technology-push approach. A similar reasoning is applied to the professional component of the "social gains" driver (i.e., the opportunity to gain prominence and opportunity for personal growth) mentioned by Compagni et al. (2015) ${ }^{4}$. Although this reflects the recognition of personal rather than business benefits tied to new technologies, it still contains the core aspect of appreciating what new technologies can potentially offer, which can push action.

4 We consider the organisational part of the social gains code (e.g., search for organisational visibility) mentioned by Compagni et al. (2015) as embedded in the 'general' understanding of the TP approach. That is, the recognition of new technologies as a means to improve the performance of an organisation. 


\subsection{Need-Pull}

An alternative to the TP model is the need-pull (NP) model which places the emphasis on the needs of a firm. The implication is that the recognition of a need is what motivates adoption. The importance of this approach can be found in the danger associated with the TP approach discussed above. This statement is strengthened by the fact that Chau and Tam (2000, p. 231) mention a study by Meyers and Marquis, published in 1969, that reported "that more than $70 \%$ of the innovations could be classified as need-pull, and suggested that organisations should pay more attention to needs for innovation". The relevance of the NP model is also reflected in the fact that the frequently cited work "diffusion of innovation" by Rogers (1983) incorporates the NP concept in its innovation-decision process model through the prior condition of "felt needs/problems".

One source of a firm's needs is the environment. First, the microenvironment (i.e., market and industry) plays a role as evident from the classic, but still widely applied, five forces model to evaluate the environmental opportunities and threats developed by Porter (1979). This model highlights that, besides the jockeying among direct competitors, competition stems from four other sources: threat of new entrants, threat of substitutes, and the power of both buyers and suppliers (Porter 1979). Knowledge of the state of these five forces can aid managers in identifying possible or necessary strategic actions (Porter 2008) or, in a needs terminology, it points to prospective and urgent needs. The alternatives to the technology-push approach as briefly addressed in the introduction (i.e., perceived market opportunities, demands from large customers, the old-fashioned method as a competitive advantage $^{5}$ ) are thus examples of needs stemming from the firm's microenvironment. Additional needs appear when extending the environment to the macrolevel. Here, changes in aspects such as regulations, demographics and sociocultural trends (e.g., rising environmental consciousness) are also expected to bring about needs/problems.

A second source of needs stems from elements internal to an organisation. Every organisation has a certain vision and mission, a culture and a reputation. These aspects are connected to the core of an organisation and, as such, are expected to be able to bring about a need if that which is proposed aligns with the core of the organisation: a need to act in a manner fitting the firm's identity. Support for this expectation can be found in the "organisational imperative" motivational driver identified by Compagni et al. (2015). This has a cultural part (coherence with organisational values and the organisation's mission) and a reputational part (such as coherence with a reputation for technological leadership). Organisational resources are not limited to those mentioned so far. According to Barney (1995, p. 50), a firm's resources include "all of the financial, physical, human and organisational assets used by a firm to develop, manufacture and deliver products or services to its customers". However, although some resources may be essential to a firm — that is they are valuable, rare, imperfectly imitable and have no strategically equivalent substitutes-they are not all expected to operate as factors that will generate a need to adopt Industry 4.0. Some may pose challenges with respect to the implementation phase (as is seen in existing publications) or, given that the possible Industry 4.0 outcomes are extensive since they contain three broad technology-based developmental streams, they may act as a support factor and/or direction indicator for the specific choices that firms make regarding Industry 4.0 content.

\subsection{Integrated Approach}

Besides the technology-push and need-pull approach, some researchers have proposed that "a successful innovation would occur when a need and the means to resolve it simultaneously emerge" (Chau and Tam 2000, p. 231). Munro and Noori (1988) refer to this as an integrated approach as it considers both the push and pull approach. That is, it matches the potential benefits or means of a new technology (TP) with the needs that a firm is facing (NP).

5 Note that, in the latter case, there is a clear absence of a need, and thus a good reason not to adopt Industry 4.0. 
The above is summarised in Table 1.

Table 1. Summary of the variation in technology adoption drivers.

\begin{tabular}{ccc}
\hline Technology-Push Approach & Need-Pull Approach & Integrated Approach \\
\hline Expected organisational & Environmental elements: & \\
benefits from technology & Micro- and macro- components & Combining technological means \\
Appreciation for technology & Internal context: & and organisational needs \\
from personal values & Core aspects of an organisation & \\
Expected personal gains & & \\
from technology & & \\
\hline
\end{tabular}

\section{Method}

\subsection{Case Selection and Procedure}

In our case selection and data gathering, we made use of a specific part of the Dutch national and eastern regional platform for Industry 4.0 (also known as Smart Industry in the Netherlands). The websites of both platforms are openly accessible (i.e., smartindustry.nl and smartindustryoost.nl). On their websites, the platforms feature a section highlighting "smart companies". Each presents a set of organisations that are leaders in the adoption of Industry 4.0 and, in so doing, they form an ideal initial case set ${ }^{6}$. Additionally, for each of the stated organisations, the websites provide intriguing data in the form of interview transcripts, text based on conducted interviews and/or video material.

Before turning to assess the data, an initial selection was made based on whether the organisations were a provider or a user of Industry 4.0. Given that our research is aimed at motives underlying the decision to opt for Industry 4.0, those that were categorised as providers-for instance, a software service provider, data analyst or robot developer-were rejected. This removed 12 of the 34 distinct cases (three firms were present on both platforms). A further seven potential cases were rejected because they represented a Fieldlab/test facility or a network and not a single organisation. The criteria of being an individual organisation was included to limit the focus to actual Industry 4.0 activities, rather than experimental settings linked to Fieldlabs etc. Next, the available data from the remaining cases were analysed, leading to the initial deletion of ten further potential cases. This was because the data focused purely on technological aspects and/or lacked detailed insights into the reasoning behind the adoption of Industry 4.0 (a mention of only time/cost savings or increased production was considered insufficient to retain an organisation ${ }^{7}$ ). To double check that this had not omitted potentially valuable cases, a Google search was conducted for these ten cases. The search was based on the respective firm name and "Smart Industry". Within the hits obtained, we specifically looked for sources that offered interview data with members of the respective organisations; the latter was seen as some guarantee of the content's reliability. This enabled us to return two of the rejected firms, De Cromvoirtse and GS Metaal, to our case sample. The search query also yielded a grant application for another of the rejected organisations, Kornelis Caps and Closures. Given the usefulness of the presented data and the source of this hit (a national government site), this organisation was also returned to the sample set. This resulted in a sample consisting of eight cases.

For these eight cases, the firms' websites were accessed to gain additional data about the organisation itself and, where possible, the technology related to Industry 4.0 that had been adopted and the drivers behind this adoption. For instance, the website of Bruil offered details about why they made the transition, and the website of Van Raam Rijwielen contained a relevant video regarding

6 The starting pool contained available cases as presented in June 2019. Since then, the website of the regional platform, smartindustryoost.nl, has been completely restructured (in early 2020) removing the section from which our case data was retrieved. However, the interview data pertaining to all the selected cases remain accessible in a supplementary file.

7 The aim of the paper is to show the diversity in Industry 4.0 adoption drivers. Cases in which only statements of expected performance benefits were present were therefore omitted. 
their new factory. Finally, to increase the available data for the cases, the Google search query was again used. This resulted in additional data for Aebi Schmidt and Kornelis Caps and Closures. Table 2 presents company- and interview-related details.

Table 2. Company and interview details for each case.

\begin{tabular}{|c|c|c|c|c|}
\hline \multicolumn{3}{|c|}{ Company Details } & \multicolumn{2}{|c|}{ Interview Details } \\
\hline Name & \# Employees & Activities & Interviewee & Interview Dates \\
\hline $\begin{array}{l}\text { Aebi Schmidt; } \\
\text { NLD, Holten }\end{array}$ & Approx. 200 & $\begin{array}{l}\text { Main focus is development } \\
\text { and production of winter } \\
\text { maintenance vehicles }\end{array}$ & $\begin{array}{l}\text { One or combination of: } \\
\text { Production Director } \\
\text { (Holten), Director (NLD and } \\
\text { Belgium), TU/e Professor }\end{array}$ & $\begin{array}{c}\mathrm{NP} \text { - unknown }{ }^{1} \\
\mathrm{RP}-29.3 .17^{1} \\
\mathrm{O}-10.10 .17\end{array}$ \\
\hline Bruil & Approx. 400 & Concrete factory & $\begin{array}{c}\text { Market and Innovation } \\
\text { manager }\end{array}$ & $\mathrm{RP}-1.12 .16$ \\
\hline De Cromvoirtse & Approx. 60 & $\begin{array}{l}\text { Supplier of sheet metal; } \\
\text { cutting, sawing, edging }\end{array}$ & One of the owners & $\begin{array}{l}\mathrm{NP}-\text { unknown } \\
\mathrm{O}-23.11 .15\end{array}$ \\
\hline GS Metaal & Approx. 40 & $\begin{array}{l}\text { Metalworking company, } \\
\text { specialised in laser cutting, } \\
\text { edging, welding }\end{array}$ & One or both directors & $\begin{array}{l}\mathrm{NP} \text {-unknown } \\
\mathrm{O}-7.5 .18\end{array}$ \\
\hline $\begin{array}{l}\text { House of Blue } \\
\text { Jeans }{ }^{2}\end{array}$ & $?$ & Clothing store & Owner & $\mathrm{NP}$-unknown \\
\hline Itter & Approx. 40 & $\begin{array}{l}\text { Core competence machining } \\
\text { aluminium }\end{array}$ & One or both owners & $\begin{array}{l}\text { NP-unknown } \\
\text { RP-29.3.18 }\end{array}$ \\
\hline $\begin{array}{l}\text { Kornelis Caps } \\
\text { \& Closures }\end{array}$ & Approx. 50 & $\begin{array}{l}\text { Develops and produces caps, } \\
\text { lids and closures }\end{array}$ & $\begin{array}{c}\text { One or combination of: } \\
\text { Production manager (new } \\
\text { construction), Director of } \\
\text { GotoGemba }\end{array}$ & $\begin{array}{l}\mathrm{RP}-30.1 .18 \\
\mathrm{O}-23.11 .17\end{array}$ \\
\hline $\begin{array}{l}\text { Van Raam } \\
\text { Rijwielen }\end{array}$ & Approx. 130 & $\begin{array}{l}\text { Manufacturer of adapted } \\
\text { bicycles }\end{array}$ & Financial/HR director & $\begin{array}{c}\mathrm{NP}-\text { vid 25.1.17 } \\
\mathrm{RP}-18.10 .17\end{array}$ \\
\hline
\end{tabular}

Abbreviations: $N L D$ is the Netherlands; $N P$ is the Dutch national platform; $R P$ is the eastern regional platform; $O$ are other interview sources; TU/e stands for the Eindhoven University of Technology; and vid means video. ${ }^{1}$ Both sources contain near-identical texts; ${ }^{2}$ The Facebook page of this company can be considered as the firm's website.

\subsection{Data Analysis}

The available data for each case (see Appendix A and Supplementary File) were analysed based on several factors. First, to gain an understanding of how firms embedded the Industry 4.0 phenomenon in their organisation, statements related to this were collected (as an Industry 4.0 variable). The data were also analysed based on the factors displayed in Table 1. In other words, the variables used were: organisational benefits (i.e., statements that reflect Industry 4.0 in general, or its outcomes in a positive manner for firms); personal values (i.e., statements depicting a favourable value or preference for technological developments in general or Industry 4.0 specifically); personal gains (i.e., remarks describing personal improvements, such as prestige or personal growth, as drivers of Industry 4.0); microenvironment (i.e., competition-related motives); macroenvironment (e.g., demographic, political or sociocultural forces offered as reasons for Industry 4.0); internal core aspects (remarks highlighting a firms vision, mission, culture or reputation as a driver for Industry 4.0); and integration (indications of a matching process). In order to obtain a general sense of the firms themselves, their organisational goals were also noted. Data on topics linked to the process of implementing Industry 4.0, such as employee participation, financial subsidies received or pilot projects, were outside the scope of this study. We did, however, note several internal resources that seemed to play a critical role as a supporting factor and/or direction indicator for the chosen Industry 4.0 direction. It was therefore decided to include these data in our analysis (as an internal supporting resource variable). The identification of information pertaining to all these variables took place over several rounds and was aided by the development of a flow chart for each case (Appendix B). The creation of these flow charts helped establish a clear overview, or representation, of each specific situation. 


\section{Portraying the Variation in Adoption Drivers of Industry $4.0^{8}$}

\subsection{Aebi Schmidt, the Netherlands}

For the company Aebi Schmidt, the observed Industry 4.0 direction was servitisation, which is highlighted as part of the Industry 4.0 promotion and a trend in itself as evident from the following quote, "In so doing we respond to the megatrends: solutions instead of products, availability instead of ownership" (Link Magazine 2017). Linked to this direction is their search for knowledge regarding the deployment of the vehicles by their clients. As part of this, the firm has equipped their grit and salt spreaders with a controller that offers up-to-date information, accessible through a web application, on performance aspects, such as spreading quantities, and on service aspects such as usage in hours or kilometres driven. It thus addresses the Industry 4.0 informed and connected streams. In aiming for servitisation, the firm went as far as defining a new mission: "improve customer performance and become a supplier of 'clean road' solutions" (Link Magazine 2017). Servitisation is one of the many performance benefits promoted by Industry 4.0 platforms (e.g., Ahsmann et al. 2018). The fact that it is framed as a megatrend potentially increases its ability to push the adoption of Industry 4.0. The observation of the "servitisation" megatrend can thus be considered an organisational benefit-related technology-push aspect.

The data obtained further suggested that the observed transition is connected to European regulations surrounding its customers. Due to the use of mandatory tenders, Aebi Schmidt and similar companies require a unique sales approach for their customer base. The obligatory use of tenders creates a specific form of competition in which, according to the Dutch public procurement expertise centre, the focus is often on "following tendering rules and opting for the lowest price" (PIANOO 2019). This explains the statement that signalled Aebi Schmidt's re-evaluation of what their customers would be willing to pay for: "Traditionally, making the best machines is the aim of many machine builders. But do customers want to pay for this? After all, it is not about the quality of the machines, but about the results they achieve." (Link Magazine 2017) and "In the end, they find a clean, safe road in winter conditions much more important than having a spreader or sprayer" (Boost_AS 2017). In addition, it was found that the organisation holds to the central tenet of "can it be done differently and (as a result) better" in everything they do. Given that this central question is asked of everything they do, it can be considered as a form of organisational culture. As such, this aspect reflects an internal need-pull. On the other hand, the price-oriented competition that originates from the mandatory tendering process is an example of a microenvironmental need-pull while also explaining the attention given to the servitisation megatrend. That is, the price competition embedded in the tendering makes it impossible for Aebi Schmidt to change the type of competition. Competing with a new form of price offer (i.e., servitisation), thus becomes a logical step. It also signals the presence of an integrated approach-matching the benefits of Industry 4.0, in the form of servitisation, with the need to break away from the existing price-based competition.

The data collected further contained indications of two supporting factors for the Industry 4.0 direction chosen. One is the service- and data-oriented mindset that the organisation appeared to possess, as visible in the quotes "it has been offering full-service contracts to clients for 30 years" and "a precondition for successful servitisation is also digitalisation, for access to the data generated by the machines. On this point Aebi Schmidt appears to have had foresight: thirty years ago, it already put a memory card in its machines" (Link Magazine 2017). The second is the apparent long-term use of the modularisation concept. The statement "We cannot use the fact that our machines have a modular structure as a sales argument" (Link Magazine 2017) suggests that this concept existed prior to their servitisation decision. The fact that modularisation aids the servitisation decision is supported by the continuation

8 In this section, a distinction in the representation of quotes is made to distinguish direct quotes from organisational representatives (in italic) from those that reflect what the author of an article (i.e., the interviewer) has written (non-italic). 
of the previous quote "but we can offer to unburden the customer in their maintenance, ..., which in turn is due to this modularisation" (Link Magazine 2017).

Table 3 presents an overview of the adoption drivers and supporting resources found.

Table 3. Summary of the adoption drivers for Aebi Schmidt.

\begin{tabular}{ccc}
\hline Technology-Push Approach & Need-Pull Approach & Integrated Approach \\
\hline Servitisation megatrend & $\begin{array}{c}\text { Price competition due to } \\
\text { mandatory tendering } \\
\text { Organisational culture of innovation }\end{array}$ & $\begin{array}{c}\text { Matching megatrend with } \\
\text { price competition }\end{array}$ \\
\hline & Internal supporting resources \\
Modularisation \\
Service- and data-oriented mindset
\end{tabular}

\subsection{Bruil}

The dominant Industry 4.0 direction for Bruil is their decision to adopt 3D technology to start printing concrete. The consequences of this decision not only involved the self-development of a 3D concrete printer with which they wish to put their own stamp on 3D printing: "Our 3D printer is currently delivering comparable results to other well-known 3D concrete printers in the world. But the bar is slightly higher. Within a few months we expect to be able to show the first results of our own vision on this topic" (News November 2015). It has also ensured that the organisation had software developed that could convert the 3D models of architects into print paths_- "Today's architect no longer designs, but programs. What is easier than sending digital designs directly to a concrete printer that prints the designs immediately?" (Boost_B 2017). In addition, Bruil is currently building a prefab printing factory to enable a broader approach (e.g., larger and mobile printers) in their 3D printing. The 3D printing component reflects the equipped stream of Industry 4.0, while the notion of the digital print paths fits the connected stream.

The initiative to adopt 3D printing technology can be traced back to the 2014 reconsideration of the organisation's strategy. In this, they concluded that some of their products were not sufficiently distinctive, the main focus in recent years had been on reducing losses, leading to the insight that they had to innovate in order to escape the stranglehold of a market dominated by price competition. The identified market situation can be traced back to the crisis that started in 2008 as evident from the following quote: "Ultimately, everyone can make concrete. During the crisis we could, therefore, only compete on price" (Boost_B 2017). The conclusions, in combination with a sector assessment-depicting the sector as traditional, low tech and with an extremely long chain-resulted in a change of direction in which the goal became "To need only half of the primary raw materials within 10 years with the aid of smart processes and products" (Boost_B 2017). The step from identifying this goal to adopting 3D technology can be attributed to the innovation trajectory which Bruil followed. That is, with the aid of a clear innovation process—-specifically the selected "FORTH" innovation method-they searched for products, services and/or sectors that were new to them and could be distinctive on the market.

To summarise (Table 4), the decision to invest in 3D printing technology was influenced by the price-oriented competition that stemmed from the economic crisis in 2008, reflecting a microenvironmental need-pull. The observed innovative trajectory which, in essence, led the organisation towards 3D printing signals the presence of the integrated approach. Although this trajectory included a broader search objective by not just considering technological solutions, the innovative trajectory does represent a process of matching a need and a means. 
Table 4. Summary of the adoption drivers for Bruil.

\begin{tabular}{ccc}
\hline Technology-Push Approach & Need-Pull Approach & Integrated Approach \\
\hline & Price competition stemming from & $\begin{array}{c}\text { Innovative trajectory to match a } \\
\text { economic crisis }\end{array}$ \\
\hline
\end{tabular}

\subsection{De Cromvoirtse}

In the De Cromvoirtse organisation, Industry 4.0 is reflected in their people-light approach to the production chain: "to do this, you must be able to recognise a customer's drawing, convert it into a quotation using software, then automatically have the right materials removed from the warehouse, have it processed, packaged, etc." (Van Ede 2015). With the aid of smart machines and the connection of various ICT systems, they have managed to automate the entire process from quotation request to production. The main focus appears to reflect the connected stream of Industry 4.0. However, the following quotes emphasise that the equipped and informed streams also seem to play a role: "supply and removal takes place with robot cars. Not only must the correct plates be collected automatically, residues must then be stored again for later use" (Van Ede 2015) and "the remnants that remain are recognised and stored. The moment material is cut again, it is checked whether the stored material can be re-used" (National platform_DC n.d.)

The first step towards adopting the above process was made in 2008. Nevertheless, at that point, they did not envision their current reality. Back then, the company experienced that the scale of a drawing had been improperly copied with an incorrectly dimensioned production series as result, and some customers wanted the firm to be available for calculations in the evening. These two aspects were the stimulus for deciding to build an automatic calculation and quotation system: "In retrospect, we then built the first link in our people-light order and production chain" (Van Ede 2015). The advance from this initial step to the automated process the organisation currently possesses was a gradual one. It was one that never had automation as an end goal in itself. The transition was linked to their vision of delivering fast, customised metal. This vision reflects their customers' demands (i.e., rapid delivery of small series) and is tied to their period of reflection back in 2009: "We developed an important part of our vision during the 2009 recession. We used that quiet time to think about our strengths and weaknesses" (Van Ede 2015). As such, the observed transition is connected to the demands made by their customers, whose relevance was likely reinforced by the recession. The importance of the customers' demands can also be seen in a statement on the organisation's website: "metal company De Cromvoirtse is one of the most innovative metal companies in the Netherlands ... That has only been possible by listening to our customers and investing in what they need at the right time" (About us 2019). Customers can thus be seen as having occupied a position of power. This point can be further inferred from the quote: "Our customers ask for it [delivering very quickly in small series], to prevent them from getting large intermediate stocks that seize their capital, and which may later turn out to be unsaleable" (Van Ede 2015).

The demand by powerful customers for faster deliveries of small series is an example of a microenvironmental need-pull. In addition, the existence of an automated calculation/quotation system is seen as a factor supporting the Industry 4.0 direction chosen by functioning as a sort of stepping stone towards creating a people-light order-to-production chain (see Table 5).

Table 5. Summary of the adoption drivers for De Cromvoirtse.

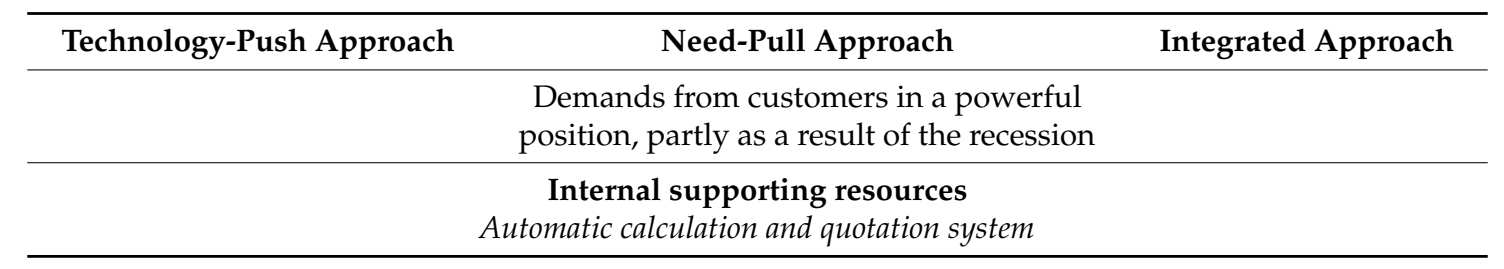




\subsection{GS Metaal}

For the GS Metaal company, the Industry 4.0 direction highlighted is the realisation of a digital factory involving a multi-year trajectory. One aspect is the installation of software from Axoom that includes a cloud-based shell that will cover the entire business process, and digitally connects all the information on every activity. A precondition for the introduction of this software is the presence of lean manufacturing. Consequently, the organisation first underwent this step, as indicated in an article and reflected in the heading of a news bulletin on the firm's website, "LEAN training" (News November 2018). GS Metaal further aims to increase its capacity by digitally connecting customers and suppliers. A current example is that communication with a specific supplier recently started to proceed through EDI (electronic data interchange). In addition, the organisation has plans to build a portal to expand digital communication with external parties. Finally, it is indicated that additional investments will be made at a later stage. A prominent role is thus apparent for the Industry 4.0 connected stream.

A key observation for this organisation is reflected in the following statement: "Nowadays a metal company can no longer distinguish itself to the customer on the basis of the quality of its cutting, milling, welding and lace work, knows Jan van de Maat [director]. All the more with shorter delivery times and higher delivery reliability" (Link Magazine 2018). As the original data source did not provide background details for this shift, an additional Google query was performed to find an explanation. This yielded the following insight from an article on the ABN-AMRO website: "competitive pressure has increased, partly due to the quality improvement of many foreign producers" (Burgering and Kemps 2016). Foreign players thus seemed to have caught up, aligning competition dimensions, and clarifying the statement made. Based on a visit to Axoom in 2017, the directors of GS Metaal came to the conclusion that the solution to the issue raised above should not be found in machines (e.g., bigger or faster) but in making the internal logistics process more efficient and effective, as well as in the better use of data (this signals the presence of the informed stream of Industry 4.0). Consequently, this visit led to the development of a multi-year, digital factory trajectory with, as its main goal, "increasing the production capacity in order to serve existing and new customers faster and more reliably" (Link Magazine 2018). Specifically, they set a target of achieving a 30\% increase in production capacity by 2019. The article also addressed two secondary goals. First, they wanted to move closer to the customer. Based on the article, there seems to be no clear cause for this other than an indirect effect. It was stated that, by enabling their employees to work more effectively and efficiently, they would save time which can then be spent on customers to improve product manufacturability. The second additional goal is explained in the following statement, "GS Metaal primarily goes through this complex process for its own customers, .... But the metal company has also taken up the challenge in favour of fellow companies, says Hofmeijer [director]" (Link Magazine 2018). In collaboration with Axoom and Trumpf, the firm is setting up an experience centre.

To summarise (Table 6), the realisation of a digital factory was driven by an observed shift in aspects of quality as a result of changes in the operations of their international competitors. This initiated a new focus (i.e., quicker and more reliable deliveries) that needed to be realised. This reflects a microenvironmental need-pull. The fact that a digital factory was considered to be the solution to the problem arose from a visit to the consulting firm Axoom. This consulting firm can therefore be seen as an influential player in a matching process (i.e., connectivity rather than bigger or faster machines) that is indicative of an integrated approach.

Table 6. Summary of the adoption drivers for GS Metaal.

\begin{tabular}{lcc}
\hline Technology-Push Approach & Need-Pull Approach & Integrated Approach \\
\hline & $\begin{array}{c}\text { International competition requiring a } \\
\text { new distinctiveness direction }\end{array}$ & Axoom dominated matching process \\
\hline
\end{tabular}




\subsection{House of Blue Jeans}

Of our sample, House of Blue Jeans, presents a relatively unique case since it is the only service-oriented firm included and, given its lack of chain connections, can be considered a micro-business (i.e., fewer than 10 employees). Nevertheless, the store contains a relatively large number of technologies related to Industry 4.0. It accepts payments through DigitByte, and the article referenced further highlights that: 1 . "when you place a piece of clothing on the wooden box next to the full-length mirror, 360-degree photos automatically appear on the mirror"; 2 . "by moving your finger over the photo, you can virtually rotate the article and view it from all sides. And you immediately get combination suggestions"; and 3. "thanks to iBeacons, the system already knows who is in the fitting room, as long as the customer has downloaded the app on his smartphone. There is a screen in the fitting room on which the photos of the item of clothing appear as soon as you hang it on the wall. The screen offers more options, so you can ask the seller to bring a different size and you can already pay for your purchases. If you put a pile of clothing on the counter, the total amount will appear on the counter within two seconds" (National platform_HBJ n.d.). These features primarily address the Industry 4.0 connected stream.

The motivation for these developments arose from the owner's preferences. The owner was inspired by the fact that technology is evolving so fast, and this drove an intention to adopt it in his store. In other words, the decision to incorporate Industry 4.0-related technologies in the clothing store stems from a value held by the owner that reflects a personal value-related technology-push. The actual realisation of this inspiration can be traced back to a good friend who told the owner about Tofugear-a Hong Kong based digital solutions provider focused on the commerce sector. As a result, this friend constitutes an important factor to the observed changes related to Industry 4.0 since their content might have been different without the friend's remark. This is evident from the level of influence that Tofugear possessed: "before Hauser [the owner] knew it, House of Blue Jeans was a demo shop where Tofugear could demonstrate all its gadgets to potential customers and other interested parties" (National platform_HBJ n.d.).

An overview of the identified adoption driver and supporting resource is presented in Table 7.

Table 7. Summary of the adoption drivers for House of Blue Jeans.

\begin{tabular}{|c|c|c|}
\hline Technology-Push Approach & Need-Pull Approach & Integrated Approach \\
\hline \multicolumn{3}{|c|}{ Owners fondness of the visible rapid technological developments } \\
\hline $\begin{array}{l}\text { Intern } \\
\text { Suggestion }\end{array}$ & $\begin{array}{l}\text { urces } \\
\text { by a friend }\end{array}$ & \\
\hline
\end{tabular}

\subsection{Itter}

In contrast to the other cases, with Itter, the level of detail regarding the Industry 4.0 transition remains rather abstract. The articles obtained from both the national and regional Dutch platform mostly use the word automatisation. One article included the quote, "Robots are also the new colleagues at Itter" (Boost_I 2018). However, the capabilities of these robots remain unaddressed. In addition, the organisation's website only offers the following, general statement: "we are increasingly automating our processes where possible. The administrative processes as well as the production processes" (Automation n.d.). Nonetheless, their "people-light production" goal signals the potential presence of smart machines. In addition, a highlighted future vision indicates the possible existence, or at least the future intention, of an intelligent, connected production process. "I envision that our customers will control our production process from behind their computer. And I see AGVs (automatic guided vehicles) driving around in a completely people-light factory" (Boost_I 2018). This statement emphasises the presence of the Industry 4.0 connected and equipped streams.

An implicit motive is maintaining production in the Netherlands, since it is mentioned that "Robots are also the new colleagues at Itter. Because only by automating you are able to produce 
cheaper and thus keep production in the Netherlands" (Boost_I 2018). However, the link to Industry 4.0 is based on inferences (there is no direct evidence that the robots linked to this statement fit Industry 4.0 technologies) and, as switching to robots is not in itself a new concept, this motive is not taken into account. The reason for adopting "automatisation" can also be traced to a preference for technological development held by the founder of the organisation: "I have been fascinated by new technologies all my life. Not only when it comes to innovations in the metal industry, but actually in every area. We put that preference for progress into practice in our smart factory"; "I have always been innovative. I always wanted to lead the way"; and "People call me a dreamer. I can fantasize enormously about the future" (Boost_I 2018; National platform n.d.). According to the organisation's website, the power to make decisions seems to be located with the founder and, since 2009, his son (the employees part of the website shows a planner, coordinator and production leader but no other management members). Given that the founder is still involved and that the other decision-maker is his son, the founder's values are likely to have driven the decision to adopt Industry 4.0. As a result, it reflects a personal value-based technology-push. Data also showed that, in 2000, the founder made a conscious decision to specialise because "it allows you to really add value for your customers" (Boost_I 2018). Based on the following statement, we deduce that the one-piece flow goal mentioned is linked to their specialisation direction: "What was standard for us-and is now called 'smart' - is that we are an extension of the R\&D department of our relations. With the aim of producing single pieces at the cost of batch production. A one-piece flow" (National platform_I n.d.). It would appear that specialisation is likely to be a reputation that the organisation aims to uphold. In so doing, it expresses an internal need-pull which appears to be supported by the abstract statement "to remain special, the owners embraced Smart Industry" (National platform_I n.d.).

Table 8 presents an overview of the identified adoption drivers.

Table 8. Summary of the adoption drivers for Itter.

\begin{tabular}{ccc}
\hline Technology-Push Approach & Need-Pull Approach & Integrated Approach \\
\hline Founder's fascination for technological development & Retain expert reputation & \\
\hline
\end{tabular}

\subsection{Kornelis Caps and Closures}

This organisation's Industry 4.0 transitions were concentrated in their new smart factory where everything would be centred around "continuous monitoring, analysis and control of production data" (Boost_KCC 2018). It was to become a factory that "constantly monitors the condition of the machines, predicts maintenance and generates the big data with which it can produce more efficiently" (Verpakkings management 2017). To realise such an outcome, the organisation packed their machines with sensors, created an intelligent operating system and replaced fixed screens with tablets. The level of connectivity realised becomes clear from the following quote, "The idea that, soon, customers will place an order and the machines will then find the most ideal production sequence themselves..." (Boost_KCC 2018). After the realisation of this smart factory, the next project is directed towards their storage facilities since the plan is to build a new automatic warehouse that includes AGVs. The goal that Kornelis aims to achieve with all these changes is fast and error-free manufacturing. "The future focus at Kornelis is mainly directed towards smart business. Fast and error-free manufacturing of standard and customized products, according to the requirements and specifications supplied by customers. We will be able to make this step in our new smart factory" (Boost_KCC 2018). It is also anticipated that their machines will be better used as reflected in the goal of "an even higher productivity that, in terms of quality, meets the strictest requirements of our customers" (Boost_KCC 2018). Based on the above, this organisation reflects all three Industry 4.0 streams: informed, connected and equipped.

The grant application found in our data search highlights that "the requirements with regard to hygiene and flawless products have been tightened considerably in recent years. Hygienic production for food related products is an absolute condition. In addition, the market places increasing pressure 
on error-free production whereby 'zero defect' shifts from a wish to a requirement" (RVO 2016). What is driving these market shifts, however, is not addressed. A potential explanation for the shift to a zero-defect requirement could be the fact that the zero-defect ambition is part of the Industry 4.0 promotion (see, e.g., Ahsmann et al. 2018), and customers repeat what they hear and read. The grant application, in addition, mentioned that the company was "driven by tightening from the market and the drive to lead the way as an innovator..." (RVO 2016). The obtained data further stressed that the firm had completed the automation phase: "Of course we have already automated everything that can be automated. This enables us to produce huge numbers of caps and closures in a fast and cheap manner. But we are taking a big step further in our new smart factory" (Boost_ KCC 2018). It also pointed out that the firm possesses high-tech equipment.

To sum up (Table 9), the motivational driver for building a smart factory in which data and connectivity play essential roles stems from demands from powerful customers. This conclusion is based on the fact that the tightening of the hygiene and zero-defect requirements are highlighted as market factors and the fact that the company's products are rather standard- "You do not need to have studied higher mathematics to make our products. Everyone can do it" (Boost_KCC_2018)—which increases the potential for a shift in customer expectations to serve as a leveraging factor (Porter 2008). As such, this reflects a microenvironmental need-pull. The notion of wanting to "lead the way as an innovator" however is more difficult to interpret since it could be considered as either a value held by decision-makers or as an aspect reflecting an organisational culture. Given the uncertainty, it was decided to exclude this factor. Finally, the existing automation and high-tech equipment are resources that support the firm's choice to focus on the continuous monitoring, analysis and control of production data.

Table 9. Summary of the adoption drivers for Kornelis Caps and Closures.

\begin{tabular}{ccc}
\hline Technology-Push Approach & Need-Pull Approach & Integrated Approach \\
\hline & $\begin{array}{c}\text { Tightened hygiene and zero-defect } \\
\text { requirements from powerful customers }\end{array}$ \\
\hline & Internal supporting resources \\
Automation of everything and possession of high-tech equipment \\
\hline
\end{tabular}

\subsection{Van Raam Rijwielen}

The main reason for this organisation to adjust can be found in the growth in demand for its products: "Since 2000 we have grown around 20\% annually" (Boost_VRR 2017). Moreover, this growth is expected to continue for two reasons: "The aging population remains [this is very relevant since Van Raam makes adapted bicycles] and more people are cycling" (Province of Gelderland January 2019). A reason for the latter could be the introduction of e-bikes, which makes cycling in hilly terrains and for long distances more practical. Consequently, the organisation was looking for ways to keep up with the growth. Working "smart", or Industry 4.0, was likely seen as being able to offer that. The promotion surrounding Industry 4.0 probably contributed to giving consideration to this phenomenon since it is clearly stated that they had heard about it: "Smart Industry, of course we had already heard a lot about it but we did not have a clear picture yet of how to develop it. We then participated in the SIEBM [Smart Industry and Business Modelling] masterclass" (Smart Industry January 2017). The outputs of the masterclass were twofold. First, one of the questions raised led Van Raam to ask themselves "What can go away, what is time-consuming and therefore not working properly and which customers do not want and have to pay for" (Smart Industry January 2017). It resulted in a more streamlined inflow to the production process and the implementation of improvements on the work floor to make work more enjoyable as well as faster and with fewer errors. To realise this, the organisation automated and robotised certain processes. The question remains as to what extent this reflects Industry 4.0. As with Itter, the capabilities of these robots are not clearly addressed in the data. One aspect that does reflect Industry 4.0 is the organisation's exploration of the use of co-bots and investment in 3D printers. Second, Van Raam 
developed an e-bike app to establish better contact with their end-users. Although the Smart Industry video (January 2017) did not show a link between the app and the masterclass, one was found in an article accessed to confirm the data on the masterclass: "It was an eye opener for us [the masterclass]: we developed a business model in which we will develop services as well as products. We are currently working on an app for reading relevant data from the e-bikes; with that information we can organise the service towards the customer in a smarter — preventive—way" (Link magazine 2016). The changes made therefore address all three Industry 4.0 streams: informed, connected and equipped.

To summarise (Table 10), a driver for the observed Industry 4.0-related investments was a need to address the firm's growing product demand, which stemmed from developments in demographics and people's attitudes towards cycling. Consequently, this reflects a macroenvironmental need-pull. In addition, the promotion surrounding Industry $4.0 \mathrm{can}$, in this case, be considered as an organisational benefit-related technology-push. Though this promotion created awareness and recognition of the potential embedded in the phenomenon of Industry 4.0, or of working smart, it did not offer the firm insights into how to develop it. To obtain that clarity, they followed the SI\&BM masterclass. This masterclass ${ }^{9}$ thus played an important role in the adoption and direction of Industry 4.0 at Van Raam Rijwielen and is therefore considered as an integrated factor. In other words, it helped match the identified need with the recognised potential of Industry 4.0.

Table 10. Summary of the adoption drivers for Van Raam Rijwielen.

\begin{tabular}{ccc}
\hline Technology-Push Approach & Need-Pull Approach & Integrated Approach \\
\hline Trendiness of Industry 4.0 & Keeping up with growing demand & $\begin{array}{c}\text { Matching trend with demand } \\
\text { issue; masterclass }\end{array}$ \\
\hline
\end{tabular}

\section{Cross-Case Analysis}

By combining the case-specific tables presented in the previous section, a collective overview of the observed Industry 4.0 adoption drivers was established (Table 11). In doing so, the diversity in existing adoption drivers related to Industry 4.0 is displayed. In addition, it highlights that the personal gains driver, which we embedded in the technology-push approach, was not observed. This might be specific to the eight cases that were used in this study, or the method used to collect data, but it could also be a feature of the Industry 4.0 phenomenon. Perhaps, given their complexity and intangibility, the connected and informed streams of Industry 4.0 might not be seen as aspects that allow personal prominence and growth compared to, for instance, the robotic surgery assessed by Compagni et al. (2015).

Table 11. Collective overview of the observed Industry 4.0 adoption drivers.

\begin{tabular}{|c|c|c|}
\hline Technology-Push Approach & Need-Pull Approach & Integrated Approach \\
\hline $\begin{array}{l}\text { Expected organisational benefits } \\
\text { Servitisation megatrend } \\
\text { Trendiness of Industry } 4.0 \\
\text { Appreciation from personal values } \\
\text { Owners fondness/fascination } \\
\text { Expected personal gains }\end{array}$ & $\begin{array}{c}\text { Microenvironment } \\
\text { Destructive rivalry a } \\
\text { Powerful customer demands } \\
\text { Macroenvironment } \\
\text { Keeping up with demand coming from } \\
\text { demographics and attitude to cycling } \\
\text { Internal, core aspects } \\
\text { Organisational culture of innovation } \\
\text { Retain expert reputation }\end{array}$ & $\begin{array}{c}\text { Matching process } \\
\text { Price competition and resources } \\
\text { explain direction of identified trend } \\
\text { Innovative trajectory offering means } \\
\text { to needs } \\
\text { Consultancy-dominated } \\
\text { matching (offering means to need) } \\
\text { Combining trend with demand issue } \\
\text { (masterclass-driven process) }\end{array}$ \\
\hline
\end{tabular}

9 The masterclass shows that, besides general business modelling advice, attention was given to technological trends in the general sense (visible from the inclusion of a trend-watching company) and also specific ones as apparent from the presence of tech consultancy firms specialised in data or the production process (Smart hub academy n.d.). 
Table 11. Cont.

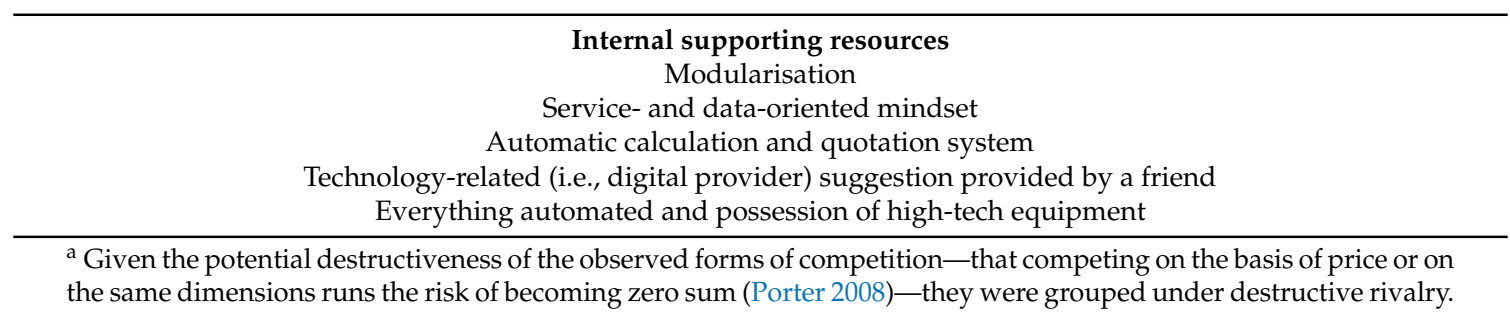

Table 11 further shows the observed directions of the microenvironmental drivers. With respect to customer demands, our data reveal that it is not the size of the customers that matters (i.e., " ... derived from demands exercised by large customers"; (Müller et al. 2018b, p. 9)), but their level of power, a finding in line with Porter (1979). This would influence the type of customers that require consideration. At the same time, it places a question mark over the conclusion drawn by Freese et al. (2018) that, in contrast to the traditional view of achieving production benefits or substituting labour, respondents now seem to emphasize the end-user as the primary driver of the deployment of new technology. Although customer demands are indeed a driver of adopting Industry 4.0, it is unlikely that all customer demands will have this effect. The same reasoning goes for the rivalry motive. It is not rivalry in itself, but the form or destructiveness of the competition that appears to drive the adoption of Industry 4.0. This suggests that we need to not only consider the common rhetoric (e.g., intensifying global competition; (Müller et al. 2018a)) but also the "content", as noted by Porter (1979). Table 11, in addition, offers insights into the type of internal supporting resources that play an essential role in the decision to adopt Industry 4.0. Representing not only the availability of technology, but also the presence of operating structures, mindsets or tips offered by friends. It also shows that these resources differ from those whose absence are seen as implementation barriers in the literature: the need for large investments, lack of employee acceptance or skills, data insecurity and technical incompatibilities.

While Table 11 offers a collective overview of the types of adoption drivers observed, Table 12 presents an overview of the combinations of adoption drivers that were detected. It highlights the prominent role of the need-pull approach, an outcome that is consistent with the early literature. As mentioned before, a study by Meyers and Marquis, published in 1969, reported "that more than $70 \%$ of the innovations could be classified as need-pull" (Chau and Tam 2000, p. 231). In addition, Table 12 leads to the following reflections related to an integrated approach. First, Combination 1 shows that the presence of a technology-push and a need-pull approach does not automatically imply the existence of an integrated approach. A company founder's fascination with technology and the need to retain an expert reputation are considered as two isolated drivers that do not have to demonstrate a matching process. Second, Combination 2 highlights that the technological means to satisfy a need not only arises from the presence of a technology-push. In two cases, the matching process involved an external party-either a consulting firm for digital transformations (Axoom) or a well-known innovation advisor (Gijs van Wulfen, founder of the "FORTH" innovation method). Third, Combination 3 appears to reflect a simple match of a technology-push with a need-pull, but of importance here is the fact that the attendance at a masterclass added weight (i.e., additional support and direction) to the observed technology-push element. Table 12 also highlights the essential role played by internal supporting resources. Similar to the masterclass, these resources acted as supporting factors and/or direction indicators for Industry 4.0. Finally, Table 12 demonstrates that all cases, apart from Itter (Combination 1), contained some form of encouragement that guided the organisations towards a specific Industry 4.0 solution-either in the form of internal resources and/or as a result of a matching process (i.e., an integrated approach). The fact that this guidance was lacking for Itter could explain why, in contrast to the other cases, the data on the chosen Industry 4.0 transition remained rather abstract for this organisation. 
Table 12. Overview of the observed Industry 4.0 adoption driver combinations.

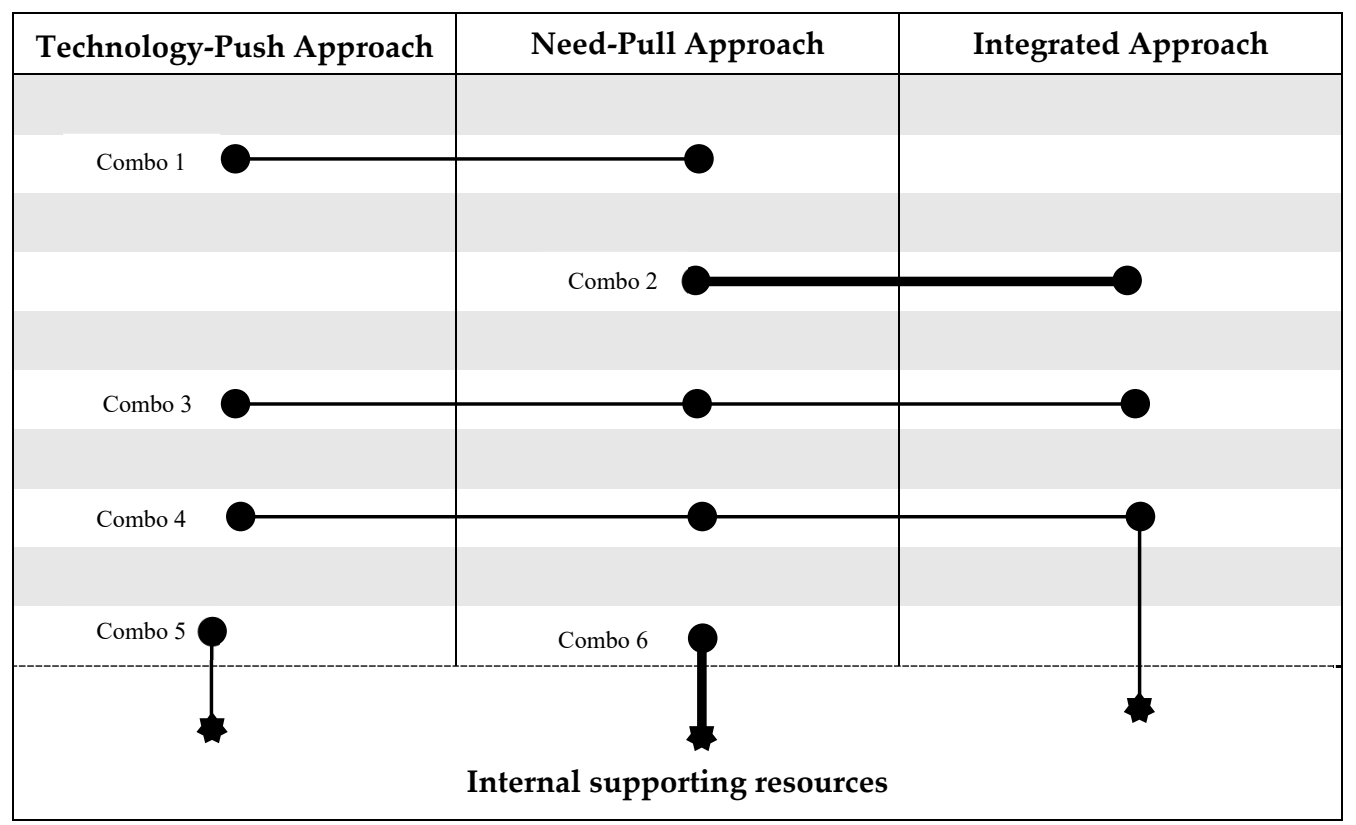

Notes: The thicknesses of the lines indicate the observed frequency, with the thin lines implying a single observation while the thick lines imply that the combination was found in two cases. The star shapes are used to indicate resources and the circles, adoption drivers.

Finally, combining the results from the individual cases emphasises the diversity of possibilities that the three technology-based developmental streams create. In other words, within just these eight cases, practices related to Industry 4.0 included: the use of resources such as 3D printers, AGVs, virtual imaging and apps; the adoption of digital forms of payment; intelligent and connected systems/machines within an organisation; digital communication with suppliers and customers; as well as the collection and relevant use of data. Given that only eight cases were assessed and that Industry 4.0 is associated with extensive exploration (as visible in the presence of Fieldlabs, etc.), these outcomes are no more than indications of what is possible, and should not be considered as an exhaustive list of Industry 4.0 directions.

\section{Conclusions}

Industry 4.0, represented as the three technology-based developmental streams currently available, is widely known and is now part of reality as reflected in the growing interest in the subject of "Industry 4.0 implementation". Yet, with respect to the drivers of Industry 4.0 adoption, it is notable that the research output to date represents a rather unilateral approach. In response, this paper has aimed to show to the scholarly and business communities that the current discussions in the literature on Industry 4.0 adoption drivers do not fully reflect the Industry 4.0 reality, which seems to be much more diverse. In other words, the goal of this paper has been to provide an overview of the broadness and variation in drivers of Industry 4.0 adoption, and this was achieved through the assessment of eight cases identified through the Dutch national and eastern regional platform for Industry 4.0.

In addition to detailed individual case descriptions, a cross-case analysis was conducted which revealed the diversity in adoption drivers related to Industry 4.0 and highlighted that there are indeed more drivers to Industry 4.0 than its expected organisational benefits. Specifically, it showed the importance of the need-pull approach as also emphasised earlier research on technological adoptions. The cross-case analysis further highlighted the relevant role that seems to be played by both internal supporting resources and external parties that dominate or drive the matching process. Consequently, organisations should not focus on just the offered promotional materials on Industry 4.0. It is recommended that they assess what urgent, or prospective, needs require things to change, and to 
combine the outcome with how Industry 4.0 could assist with this by reflecting inside the organisation and/or obtaining guidance from external sources such as technology providers, innovation consultants, technology-oriented consultancy firms or, potentially, experience centres like the one GS Metaal is setting up in collaboration with Axoom and Trumpf. The significance of internal and/or external guidance indicates that organisations appear to require assistance in adopting a specific Industry 4.0 direction. An outcome that makes sense considering the diversity of possibilities that the three technology-based developmental streams create. The prominence of external guidance, however, raises a note of caution for those organisations largely relying on external parties. In the long run, such tactics could lead to the establishment of new industry norms which would likely require further changes in order to maintain a competitive advantage.

\section{Limitations and Future Research}

One restriction stems from the limited size range of the selected cases. Based on staff headcount, all the cases apart from Aebi Schmidt, which is part of a larger cooperation, and Bruil, which in some categorisations would be labelled large, can be considered as small- to medium-sized firms. However, based on the goal of providing an overview of the broadness and variation in drivers of Industry 4.0 adoption, this limitation is not considered as a problem (i.e., we do not aim to generalise or test). Second, the selected cases are acknowledged as frontrunners with respect to Industry 4.0 and, as such, they might have overemphasized the identified innovative culture and their owners' preferences for technological development. Nevertheless, these findings depict two essential drivers of Industry 4.0 adoption and evidence the breadth and variation which we aimed to highlight. Finally, the study used only secondary data and, consequently, despite the organisations being presented as "smart companies", we have no direct observations of the Industry 4.0 directions discussed. To alleviate this limitation, use was made, where available, of videos depicting the actual situations as well as adopting a critical attitude when assessing the evidence (such as in the cases of Itter and Van Raam Rijwielen). In addition, we were aware that some of the Industry 4.0 options discussed pertained to potential steps yet to be made. In other words, the ideas had not yet been adopted in practice at the time of the reported interview. However, provided those ideas fitted with the developments linked to Industry 4.0, this was not problematic given the research goal of the paper: our interest was focused on the drivers of Industry 4.0 adoption, not the implementation process.

With respect to future research, an essential step in advancing scholarly knowledge about Industry 4.0 is to strengthen the observed findings. For instance, is the apparent lack of personal gains playing a role in this phenomenon widespread, or is it a consequence of our limited sample? Further, are the microenvironmental need-pulls as significant for the adoption of Industry 4.0 as our research suggests, and did we observe all the main types of internal supporting resources, or are there more? In addition, in line with the research conducted by Compagni et al. (2015), future research could assess the continuing presence of the adoption drivers over time. That is, can changes be observed in the prominence of observed drivers at different diffusion phases of Industry 4.0? We would also encourage extending the observations made within this study to the implementation phase. To what extent, for instance, do the identified types of drivers influence the implementation process, and how? The results highlight the influential role being played by external parties. This observation gives rise to the question, and subsequently a direction for future research, of what the long-term effects are of the prominent presence of such parties. Are they, as already suggested, driving organisations towards similar Industry 4.0 constructions? If so, what will the impact be on the competitive positions of those organisations? Finally, given the current prominence of the coronavirus, future research could consider what impact such world-changing events will have on organisations' adoption of Industry 4.0: Will it result in the creation or identification of needs for which Industry 4.0 could provide a solution (as was sometimes the case following the economic crisis around 2008)? Will the potential to generate critical implementation barriers dominate (such as emerging financial issues)? Or will the coronavirus have little effect on the adoption of Industry 4.0? 
Supplementary Materials: The following are available online at http://www.mdpi.com/2076-3387/10/2/30/s1.

Author Contributions: Conceptualization and methodology, M.H. and T.B.; formal analysis, M.H.; writing and draft preparation, M.H. and T.B.; review and editing M.H.; visualization, M.H.; supervision, T.B. All authors have read and agreed to the published version of the manuscript.

Funding: This research received no external funding.

Conflicts of Interest: The authors declare no conflict of interest.

\section{Appendix A Reference Information Regarding Case Data}

References with * are included in a supplementary data file

\section{AEBI SCHMIDT}

○ Eastern Dutch, regional, platform for Industry 4.0-Boost_AS, 2017* https://smartindustryoost. nl//wp-content/uploads/2016/12/Interview-met-Fred-Harbers.pdf

$\bigcirc$ Dutch national platform for Industry $4.0 *$ https://smartindustry.nl/wiki-smart-industry/ voorbeelden-van-ondernemers/aebi-schmidt/

Other interview source—Link Magazine, 2017* https://www.linkmagazine.nl/minder-zout-meerdata/

- Additional information-PIANOO, 2019 https://www.pianoo.nl/en/public-procurementnetherlands

Reference used to assess number of employees https://www.wv-hig.nl/leden/aebi-schmidtnederland-bv/

\section{BRUIL}

Eastern Dutch, regional, platform for Industry 4.0—Boost_B, 2017 * https://smartindustryoost.nl/ /wp-content/uploads/2016/12/Interview-met-Theo-Voogd.pdf

○ Website links-respectively News Nov. 2015 https://www.bruil.nl/over-ons/actuele-berichten/ bruil-ontwikkelt-3d-printer-voor-architectonisch-beton

Non-referenced, but used website links https://www.bruil.nl/over-ons/actuele-berichten/bruilzet-in-op-innovatie https://www.bruil.nl/over-ons/actuele-berichten/3d-geprint-architectonischbeton-op-material-xperience-2016 https://www.bruil.nl/over-ons/actuele-berichten/bruil-prefabprinting-van-lab-naar-fabriek

- Reference used to assess number of employees https://www.debanensite.nl/vacatures/bruil

\section{DE CROMVOIRTSE}

$\bigcirc$ Dutch national platform for Industry $4.0 *$ https://smartindustry.nl/wiki-smart-industry/ voorbeelden-van-ondernemers/cromvoirtse/

Other interview source-Van Ede, 2015 * https://www.procesverbeteren.nl/smart_industry/De_ Cromvoirtse_Smart_Industry.php

○ Website link—About us, 2019 https://decromvoirtse.nl/over-ons/

$\bigcirc$ Reference used to assess number of employees https:/www.promotietechniekmb.nl/decromvoirtse/

\section{GS METAAL}

Dutch national platform for industry * https://smartindustry.nl/wiki-smart-industry/voorbeeldenvan-ondernemers/gs-metaal/

Other interview source-Link Magazine, 2018* https://www.linkmagazine.nl/gs-metaal-bouwtsamen-met-trumpf-digital-factory-voor-zichzelf-en-concullegas/

○ebsite links—respectively News Nov. 2018 https://www.gsmetaal.nl/lean-training/ 
Additional information-Burgering \& Kemps, 2016 https://insights.abnamro.nl/branche/ metaalproductenindustrie/

- Reference used to assess number of employees https://www.gsmetaal.nl/bedrijfsprofiel/

\section{HOUSE OF BLUE JEANS}

Dutch national platform for Industry 4.0-National platform_HBJ, n.d. * https://www.smartindustry. $\mathrm{nl} /$ wiki-smart-industry/voorbeelden-van-ondernemers/titel-house-of-blue-jeans-gemak-grootpluspunt-van-tech/

- Non-referenced, but used video link (obtained from House of Blue Jeans Facebook) https: //www.youtube.com/watch?v=XzjMRP4DSBo

\section{ITTER}

D Dutch national platform for Industry 4.0-National platform_I, n.d. * https://smartindustry.nl/ wiki-smart-industry/voorbeelden-van-ondernemers/itter/

Eastern Dutch, regional, platform for Industry 4.0-Boost_I, 2018 * https://smartindustryoost.nl/ uploads/Nieuws/Itter\%20BOOST.pdf

○ Website links—respectively Automation, n.d. and Employees, n.d. https://www.itter.nl/machines/ automatisering https://www.itter.nl/over-itter/medewerkers

- Reference used to assess number of employees https://www.itter.nl/over-itter/medewerkers

\section{KORNELIS CAPS \& CLOSURES}

․ Eastern Dutch, regional, platform for Industry 4.0-Boost_KCC, 2018 * https://smartindustryoost. nl/uploads/Nieuws/interview\%20met\%20Ytsen\%20de\%20Boer\%20.pdf

- Grant application link-RVO, 2016 * https://www.rvo.nl/subsidies-regelingen/projecten/smartfactory

Other interview source-Verpakkingsmanagement, 2017* https://www.verpakkingsmanagement. $\mathrm{nl} /$ kornelis-transitie-naar-smart-factory

○ Reference used to assess number of employees https://meppelercourant.nl/artikel/465307/ groeiende-omzet-bij-kornelis-vraagt-om-versnelde-uitvoering-nieuwbouwplannen.html? harvest_referrer=https $\% 3 \mathrm{~A} \% 2 \mathrm{~F} \% 2 \mathrm{Fwww}$. google.com $\% 2 \mathrm{~F}$

\section{VAN RAAM RIJWIELEN}

D Dutch national platform for Industry $4.0 *$ https://smartindustry.nl/wiki-smart-industry/ voorbeelden-van-ondernemers/van-raam/ > especially the included video-Smart Industry, Jan. 2017: https://www.youtube.com/watch?time_continue=2\&v=wwM_t0pMUqY

○ Eastern Dutch, regional, platform for Industry 4.0-Boost_VRR, 2017 * https://smartindustryoost. nl//wp-content/uploads/2016/12/Interview-met-Marjolein-Boezel.pdf

○ Video by Province of Gelderland-Province of Gelderland, Jan. 2019 (via Van Raam) https: //vimeo.com/311636926

- Additional information—respectively Link magazine, 2016 \& Smart hub academy, n.d. https: //www.linkmagazine.nl/boost-smart-industry-oost-nederland/ http://www.smarthubacademy. $\mathrm{nl} /$ masterclasses/programma/

Non-referenced, but used website link https://www.vanraam.com/nl-nl/over-van-raam/innovatie

Reference used to assess number of employees https://www.vanraam.com/nl-nl/over-van-raam/ over-ons 


\section{Appendix B Case Specific Flow Charts}

\section{Legend:}

Box with a consecutive line Box with dotted line

$=$ Industry 4.0 variable

Box with full fill

=Internal supporting resource variable

Box with horizontal line full

Box with checkered fill

$=$ Microenvironment variable

=Macroenvironment variable

Box with diagonal line fill

Box with dotted fill

Bold text

Plain text

$=$ Organisational benefits variable

$=$ Personal values

=Internal core aspect variable

=Organisational goal

=Relevant extra information (e.g., indication of integration variable)

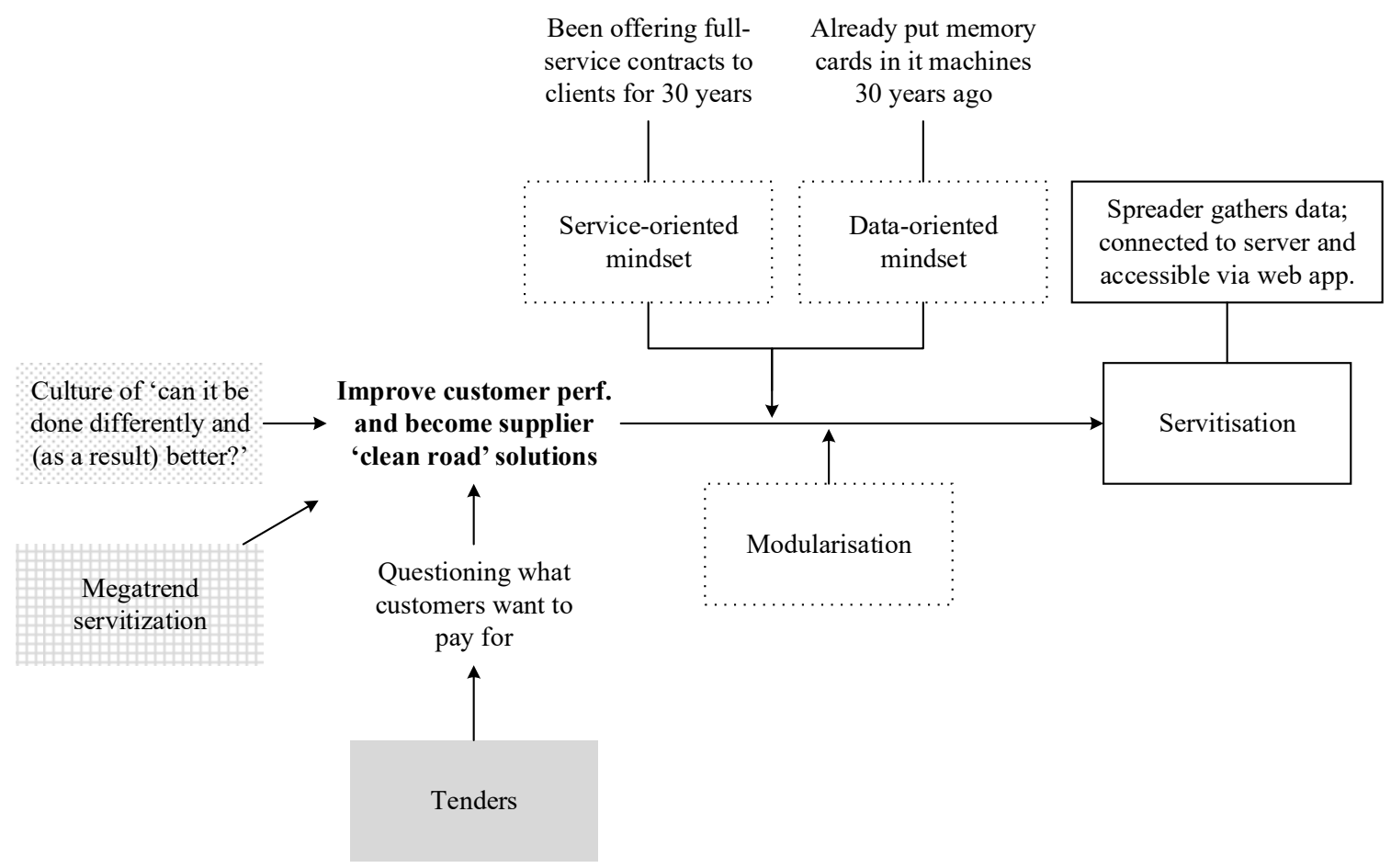

Figure A1. Flow chart for Aebi Schmidt.
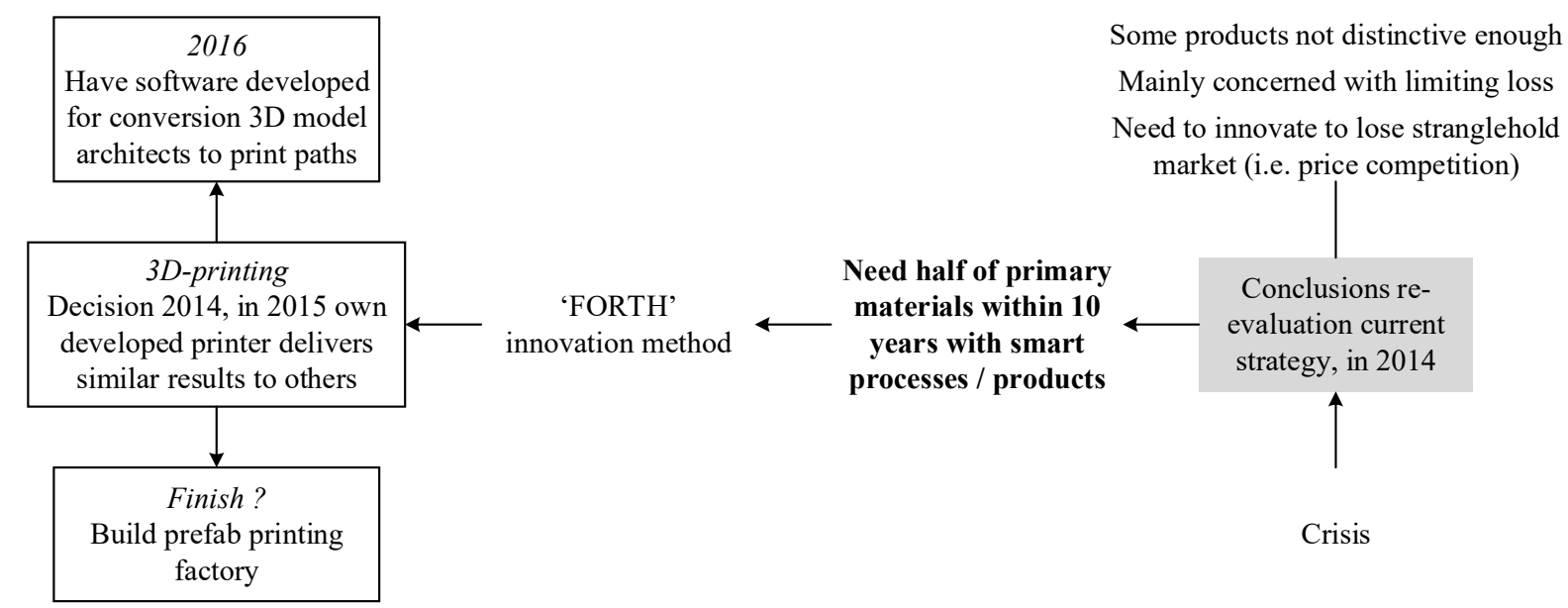

Figure A2. Flow chart for Bruil. 


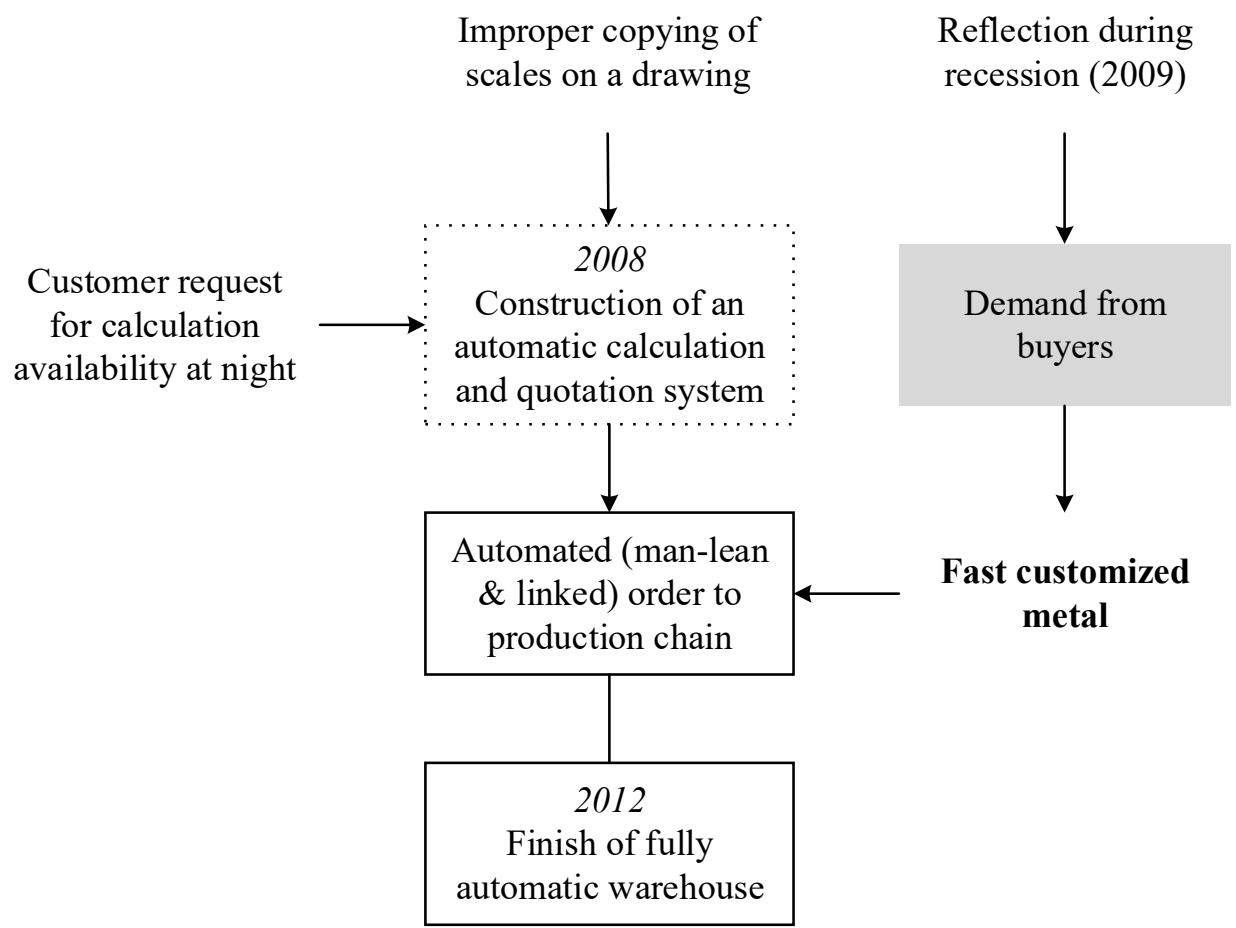

Figure A3. Flow chart for De Cromvoirtse.

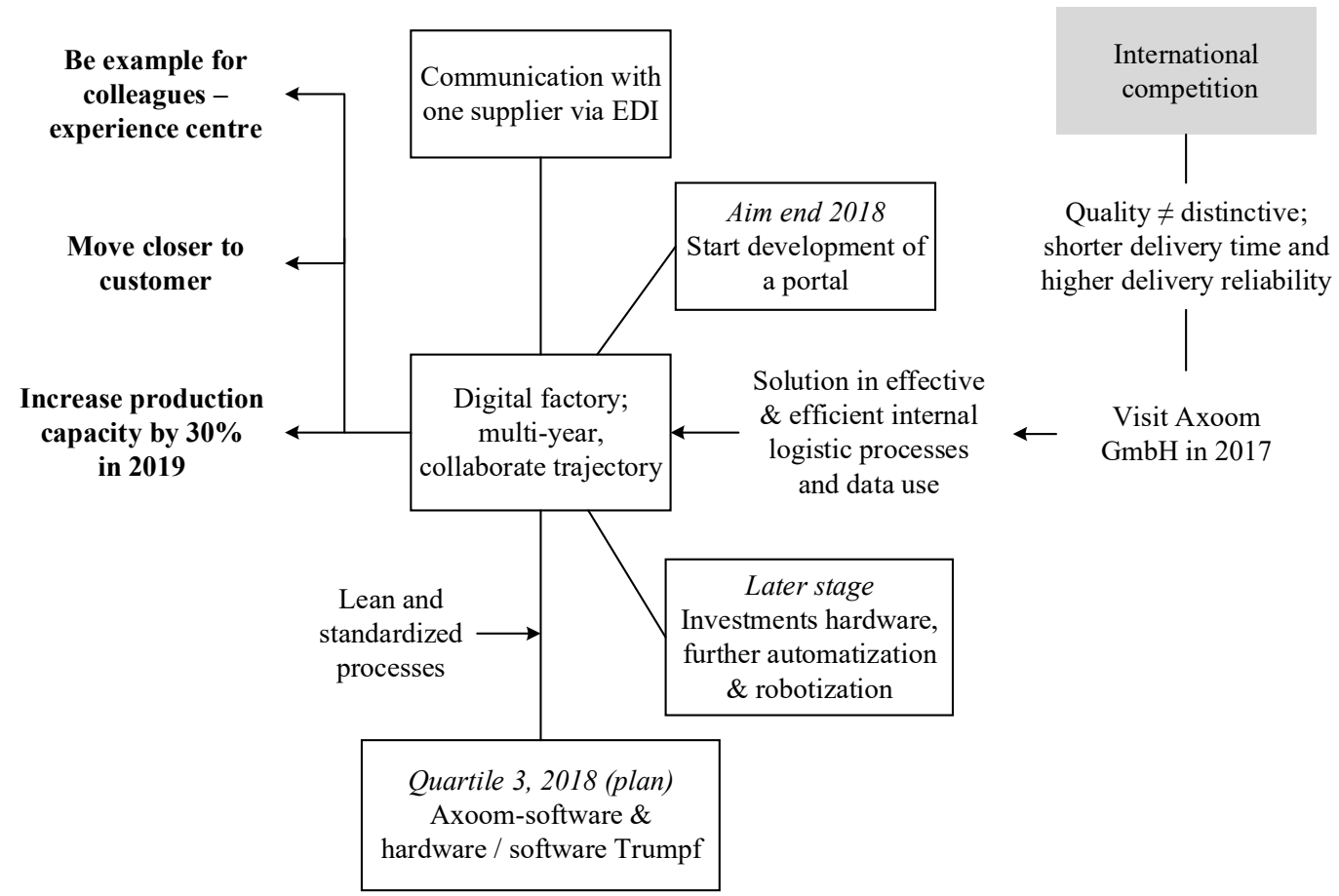

Figure A4. Flow chart for GS Metaal. 


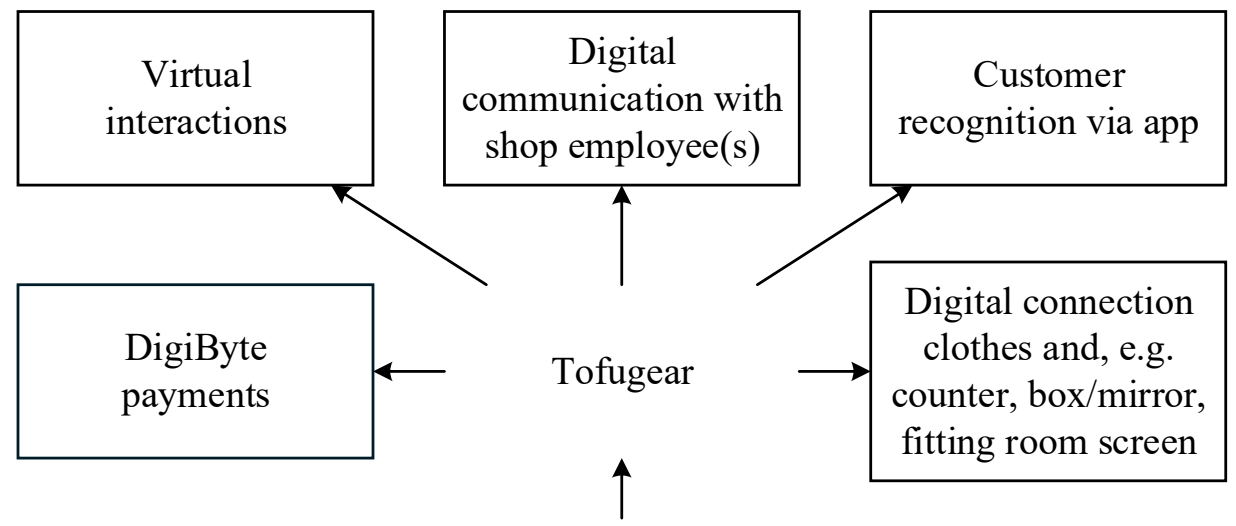

Friend

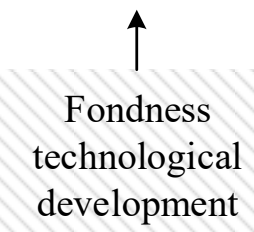

Figure A5. Flow chart for House of Blue Jeans.

In an ultimate sustainable building, we strive for manlean production and energy neutral production process

One-piece flow

Specialisation as deliberate choice in 2000

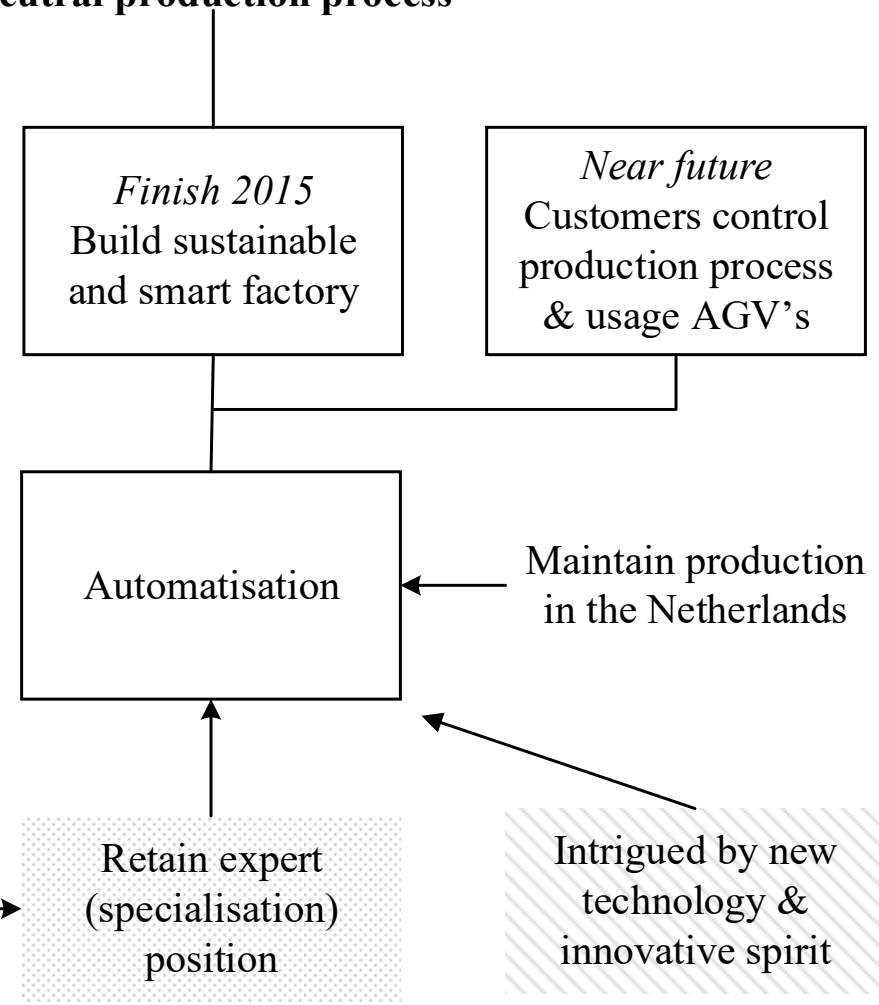

Figure A6. Flow chart for Itter. 


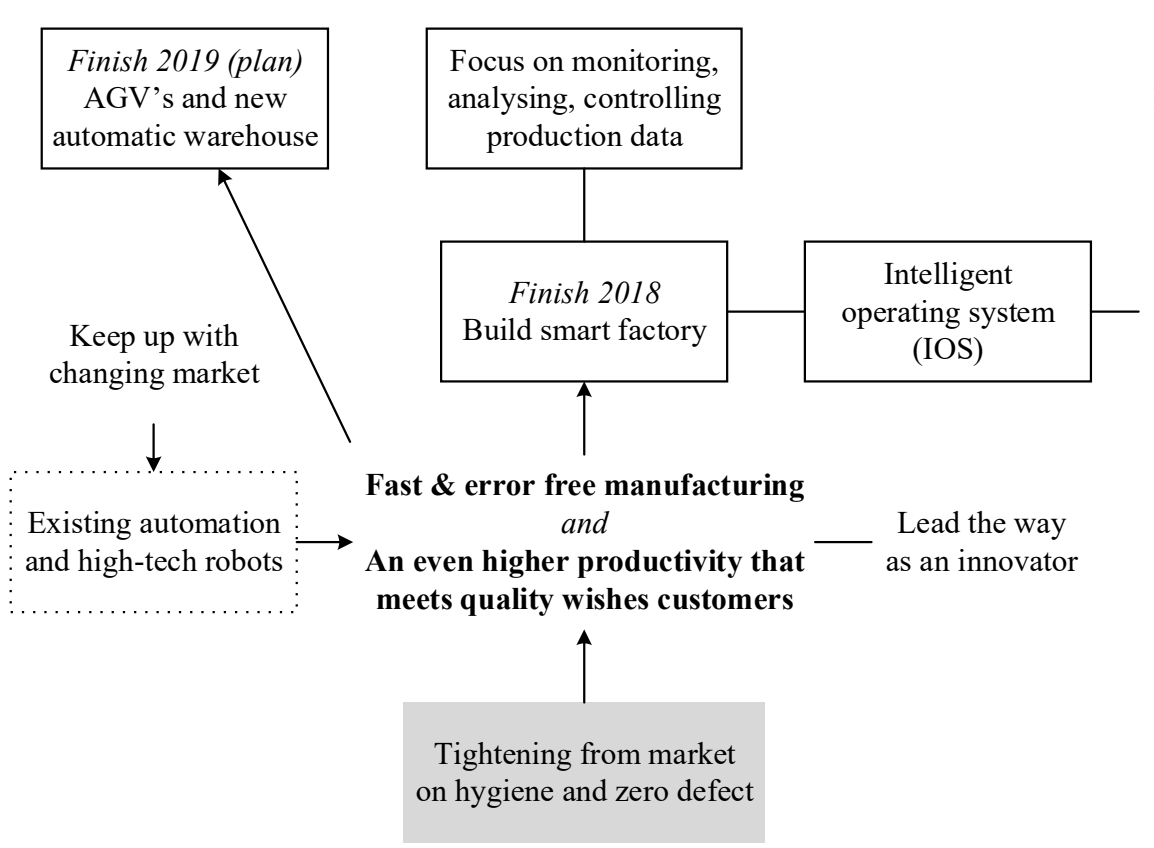

IOS can be summarized in the automation pyramid. At top is the ERP system, in middle is the MES system (international standard, ISA 95 model advantage is companies can communicate better with each other). At bottom are the actual production activities of people \& machines.

Figure A7. Flow chart for Kornelis Caps and Closures.

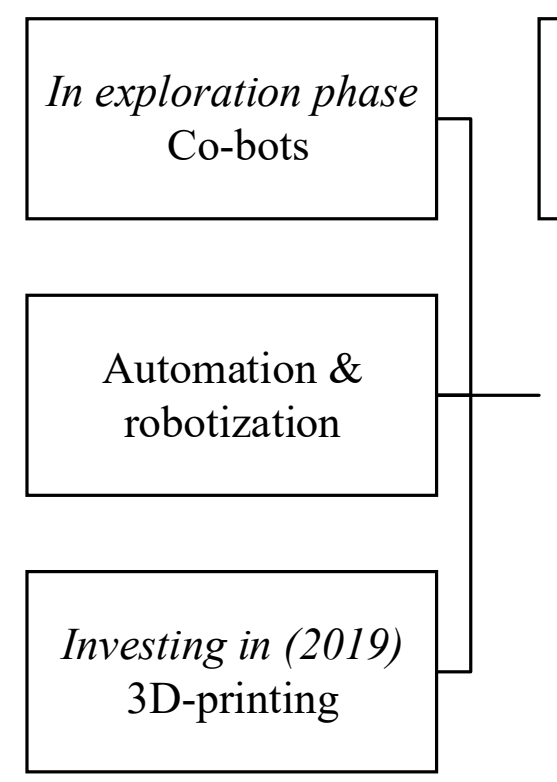

Finish 2019

Build sustainable and smart factory

Masterclass smart industry \& business modelling, in 2015

Developed app for gathering data internal processes<smiles>CCCC</smiles><smiles>CCCC</smiles>

Work smarter and cleaner

Aging population remains \& increase interest cycling

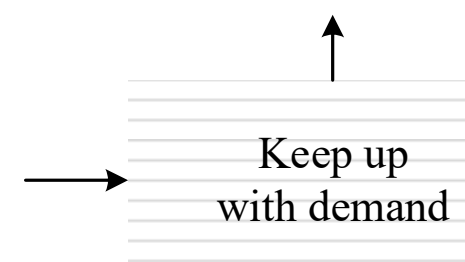

Figure A8. Flow chart for Van Raam Rijwielen. 


\section{References}

Ahsmann, Bart, Evert van den Akker, Gregor van Baars, Ruud Baartmans, John Blankendaal, Rolf Bossert, and Bert Thuis. 2018. Smart Industry Roadmap: Onderzoeksagenda voor HTSM en ICT en Routekaart Voor de NWA. Available online: https://wetenschapsagenda.nl/gecombineerde-htsmictnwa-onderzoeksagendasmart-industry/ (accessed on 12 February 2018).

Barney, Jay. 1995. Looking inside for competitive advantage. Academy of Management Perspectives 9: 49-61. [CrossRef]

Beyer, Janice M. 1981. Ideologies, values and decision making in organisations. In Handbook of Organisational Design. Edited by Paul C. Nystrom and William H. Starbuck. New York: Oxford University Press, pp. 166-202.

Chau, P. Y., and Kar Y. Tam. 2000. Organizational adoption of open systems: A 'technology-push, need-pull' perspective. Information \& Management 37: 229-39. [CrossRef]

Compagni, Amelia, Valentina Mele, and Davide Ravasi. 2015. How early implementations influence later adoptions of innovation: Social positioning and skill reproduction in the diffusion of robotic surgery. Academy of Management Journal 58: 242-78. [CrossRef]

Cordeiro, Gabrielly A., Robert E. C. Ordóñez, and Rodrigo Ferro. 2019. Theoretical proposal of steps for the implementation of the Industry 4.0 concept. Brazilian Journal of Operations \& Production Management 16: 166-79. [CrossRef]

Engelbertink, Dion, and Stijn Woudstra. 2017. Managing the Influences and Risks of Industry 4.0. Bachelor's thesis, University of Twente, Twente, The Netherlands. Retrieved from University of Twente Theses Database. Available online: http://purl.utwente.nl/essays/72705 (accessed on 21 August 2019).

Felch, Vanessa, Bjoern Asdecker, and Eric Sucky. 2019. Maturity models in the age of Industry 4.0—Do the available models correspond to the needs of business practice? Paper presented at the 52nd Hawaii International Conference on System Sciences, HICSS Conference, Maui, HI, January 8-11. [CrossRef]

Freese, Charissa, Ronald Dekker, Linda Kool, Fabian Dekker, and Rinie van Est. 2018. Robotisering en Automatisering op de Werkvloer: Bedrijfskeuzes bij Technologische Innovaties. Available online: https: //www.rathenau.nl/nl/digitale-samenleving/robotisering-en-automatisering-op-de-werkvloer (accessed on 21 August 2019).

Habraken, Milou, and Tanya Bondarouk. 2019. Smart Industry or smart bubbles? A critical analysis of its perceived value. In HRM 4.0 For Human-Centered Organizations. Edited by Rita Bissola and Barbara Imperatori. Bingley: Emerald Publishing Limited, pp. 1-20. [CrossRef]

Habraken, Milou, Tanya Bondarouk, and Dave Hoffmann. 2019. Shaking up the status quo? An analysis of developments in the social context of work stemming from Industry 4.0. In Thriving in Digital Workspaces: Emerging Issues for Research and Practice. Edited by Melinde Coetzee. Cham: Springer, pp. 197-216. [CrossRef]

Hamada, Tomomi. 2019. Determinants of Decision-Makers' Attitudes toward Industry 4.0 Adaptation. Social Sciences 8: 140. [CrossRef]

Huizinga, Geert, Liesbeth Holterman, Roos Kist, Tom Bouws, Herm van der Beek, Kristel Wattel-Meijers, and Peter van der Mars. 2018. Smart Industry Implementation Agenda 2018-2021. Available online: https://smartindustry.nl/wp-content/uploads/2019/04/SI-Implementation-Agenda-2018-English. compressed.pdf (accessed on 1 March 2018).

Machado, Carla G., Mats Winroth, Dan Carlsson, Peter Almström, Victor Centerholt, and Malin Hallin. 2019. Industry 4.0 readiness in manufacturing companies: Challenges and enablers towards increased digitalization. Procedia CIRP 81: 1113-18. [CrossRef]

Madsen, Dag Ø. 2019. The emergence and rise of Industry 4.0 viewed through the lens of management fashion theory. Administrative Sciences 9: 71. [CrossRef]

Moktadir, Abdul, Syed M. Ali, Simonov Kusi-Sarpong, and Aftab A. Shaikh. 2018. Assessing challenges for implementing Industry 4.0: Implications for process safety and environmental protection. Process Safety and Environmental Protection 117: 730-41. [CrossRef]

Müller, Julian M., Daniel Kiel, and Kai-Ingo Voigt. 2018a. What drives the implementation of Industry 4.0? The role of opportunities and challenges in the context of sustainability. Sustainability 10: 247. [CrossRef]

Müller, Julian M., Oana Buliga, and Kai-Ingo Voigt. 2018b. Fortune favors the prepared: How SMEs approach business model innovations in Industry 4.0. Technological Forecasting and Social Change 132: 2-17. [CrossRef] 
Munro, Hugh, and Hamid Noori. 1988. Measuring commitment to new manufacturing technology: Integrating technological push and marketing pull concepts. IEEE Transactions on Engineering Management 35: 63-70. [CrossRef]

Orzes, Guido, Erwin Rauch, S. Bednar, and R. Poklemba. 2018. Industry 4.0 Implementation Barriers in Small and Medium Sized Enterprises: A Focus Group Study. Paper presented at 2018 IEEE International Conference on Industrial Engineering and Engineering Management (IEEM), Bangkok, Thailand, December 16-19.

Porter, Michael E. 1979. How competitive forces shape strategy. Harvard Business Review 57: 137-45.

Porter, Michael E. 2008. The five competitive forces that shape strategy. Harvard Business Review 86: 25-40.

Rogers, Everett M. 1983. Diffusion of Innovations, 3rd ed. New York: The Free Press.

Türkeş, Mirela C., Ionica Oncioiu, Hassan D. Aslam, Andreea Marin-Pantelescu, Dan I. Topor, and Sorinel Căpuşneanu. 2019. Drivers and Barriers in Using Industry 4.0: A Perspective of SMEs in Romania. Processes 7: 153. [CrossRef]

(C) 2020 by the authors. Licensee MDPI, Basel, Switzerland. This article is an open access article distributed under the terms and conditions of the Creative Commons Attribution (CC BY) license (http://creativecommons.org/licenses/by/4.0/). 